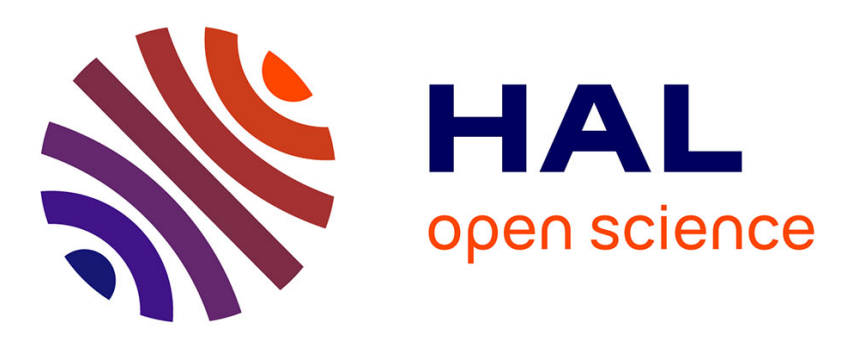

\title{
Connecting chloride solvation with hydration in deep eutectic systems
}

Maria Enrica Di Pietro, Oliver Hammond, Adriaan van den Bruinhorst, Alberto Mannu, Agílio Pádua, Andrea Mele, Margarida Costa Gomes

\section{- To cite this version:}

Maria Enrica Di Pietro, Oliver Hammond, Adriaan van den Bruinhorst, Alberto Mannu, Agílio Pádua, et al.. Connecting chloride solvation with hydration in deep eutectic systems. Physical Chemistry Chemical Physics, 2021, 23 (1), pp.107-111. 10.1039/d0cp05843b . hal-03102831

\section{HAL Id: hal-03102831 \\ https://hal.science/hal-03102831}

Submitted on 3 Mar 2021

HAL is a multi-disciplinary open access archive for the deposit and dissemination of scientific research documents, whether they are published or not. The documents may come from teaching and research institutions in France or abroad, or from public or private research centers.
L'archive ouverte pluridisciplinaire HAL, est destinée au dépôt et à la diffusion de documents scientifiques de niveau recherche, publiés ou non, émanant des établissements d'enseignement et de recherche français ou étrangers, des laboratoires publics ou privés. 


\section{Connecting chloride solvation with hydration in deep eutectic}

\section{systems}

Received 00th January 20xx, Accepted 00th January $20 x x$

DOI: $10.1039 / x 0 \times x 00000 x$

\author{
Maria Enrica Di Pietro ${ }^{a,}{ }^{\dagger}$, Oliver Hammond ${ }^{b,+}$, Adriaan van den Bruinhorst ${ }^{b}$, Alberto Mannuc, Agilio \\ Padua $^{b, *}$, Andrea Mele ${ }^{a, d^{*}}$, Margarida Costa Gomes ${ }^{b}$
}

The Deep Eutectic Solvents/Systems (DESs) choline chloride:urea $\left(x_{\mathrm{ChCl}}=0.33\right)$ and choline chloride:glycolic acid $\left(x_{\mathrm{ChCl}}=0.5\right)$ were investigated using viscosity-corrected ${ }^{35} \mathrm{Cl}$ NMR spectroscopy and molecular dynamics simulations to probe the role of chloride as a function of water content. Three $\mathrm{Cl}^{-}$solvation regimes are revealed, with high-symmetry environments for pure and highly dilute DES, and an unusual low-symmetry interstitial region where the primary coordination sphere is most disordered.

Eutectic mixtures show a melting temperature depression upon mixing, which increases the accessibility of their liquid window. ${ }^{1}$ Deep Eutectic Systems (DESs) are widely applied as a subclass of eutectic mixtures, ${ }^{2}$ defined by a eutectic temperature significantly below the ideal eutectic point. ${ }^{3}$ DES literature is mainly focused on extensively $\mathrm{H}$-bonded mixtures, ${ }^{4}$ comprising a hydrogen bond acceptor (HBA) and hydrogen bond donor (HBD). Among other hygroscopic quaternary ammonium salts, choline chloride $(\mathrm{ChCl})$, a non-toxic, widely available salt, is one of the most widely studied HBAs. The equilibrium water content of DESs ranges from ppm to significant mass fractions, making trace water unavoidable. ${ }^{5,6}$ This water acts as an additional $\mathrm{H}$ bond donor and acceptor, modifying interactions between DES components, ${ }^{5}$ and strongly affecting crucial physicochemical properties and phase behaviour.

Developing fundamental understanding of intermolecular interactions in DESs will facilitate the design of task-specific systems. The structure of DES is complex and disordered, with competing strong and weak $\mathrm{H}$-bonds between the components, ${ }^{7}$ whose contributions are poorly understood due to heavy system-dependence. A recurrent finding is that the anion, usually chloride, plays a primary role by defining the $\mathrm{H}$ -

a. Department of Chemistry, Materials and Chemical Engineering 'G. Natta', Politecnico di Milano, Piazza L. da Vinci 32, 20133 Milano, Italy.

b. École Normale Supérieure de Lyon and CNRS, Laboratoire de Chimie, 46 allée d'Italie, 69364 Lyon Cedex 07, France.

c. Department of Chemistry, University of Torino, Via P. Giuria 7, 10125 Torino, Italy

d. CNR-SCITEC Istituto di Scienze e Tecnologie Chimiche, Via a. Corti 12, 20133 Milano, Italy.

† These authors contributed equally as joint first author.

*Corresponding authors, email: andrea.mele@polimi.it; agilio.padua@ens-lyon.fr Electronic Supplementary Information (ESI) available: $\left[{ }^{35} \mathrm{CI} N M R\right.$, viscosity and MD details]. See DOI: 10.1039/x0xx00000x bond network. ${ }^{7-14}$ In the archetypal DES ChCl:urea, the local structure sees chloride in constant $\mathrm{H}$-bond flux with choline and urea, at the centre of a local cluster. The cation and HBD have different bonding affinities and short-range diffusion dynamics. ${ }^{9}$ The interaction between chloride and HBD also defines the structure of other DES such as ChCl:propylene glycol, ${ }^{15} \mathrm{ChCl}$ :malic acid, ${ }^{16}$ and $\mathrm{ChCl}$ :oxalic acid. ${ }^{17}$ The anion therefore defines physicochemical properties of DESs, ${ }^{18,19}$ and affects the DES-solute interactions. ${ }^{20,21}$ Naturally, the distribution of species bound to chloride will vary as water content changes, but this is currently poorly understood. $8,10,22$

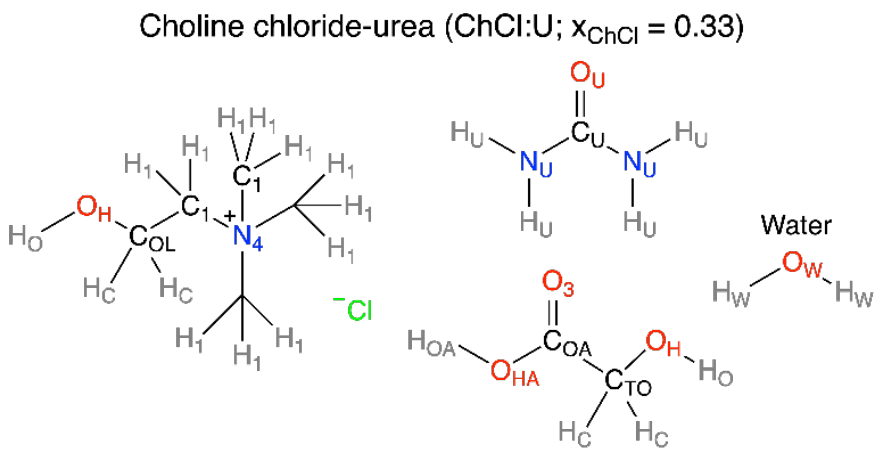

Choline chloride-glycolic acid $\left(\mathrm{ChCl}: \mathrm{G} ; \mathrm{x}_{\mathrm{ChCl}}=0.5\right)$

Figure 1. Chemical structure of the $\mathrm{ChCl}: \mathrm{U}$ and $\mathrm{ChCl}: \mathrm{G}$ DES studied in this work, and atom type labels for each molecule used in MD simulations-

Various works have investigated the $\mathrm{H}$-bond network of pure and hydrated DESs, $16,23,32,24-31$ but not specifically the environment of chloride, and how it changes with hydration. A single paper has applied chlorine NMR to some choline chloride:glycol DESs, ${ }^{33}$ which suggested weakened DES-DES Hbonds upon dilution with $\mathrm{D}_{2} \mathrm{O}$, from trends in ${ }^{35} \mathrm{Cl}$ linewidth. This study aims to directly explore how the key role of the anion is affected by the mixture's water content through connecting viscosity-corrected ${ }^{35} \mathrm{Cl} \mathrm{NMR}$ and MD simulations. Two model $\mathrm{ChCl}$-based DESs were chosen (Fig 1), choline chloride : urea $\left(\mathrm{ChCl}: \mathrm{U}, x_{\mathrm{ChCl}}=0.33\right)$, and choline chloride : glycolic acid $\left(\mathrm{ChCl}: \mathrm{G}, x_{\mathrm{ChCl}}=0.5\right)$; some critical discussion on DES nomenclature is included in the ESI $\dagger$. 
a)

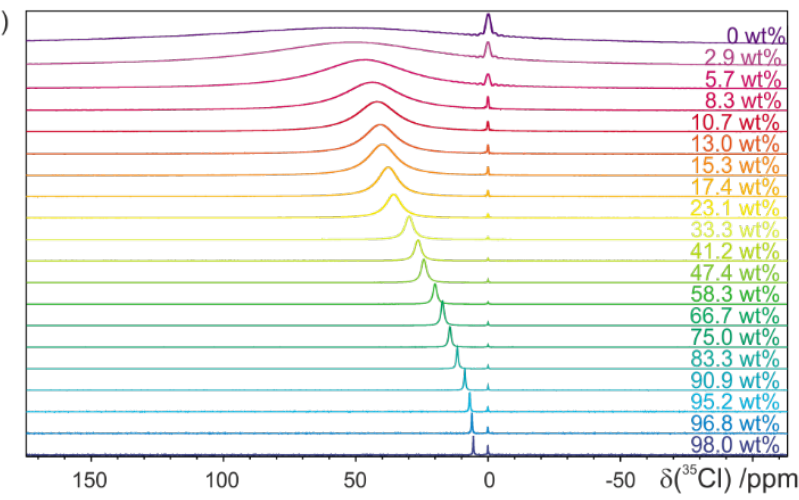

b)
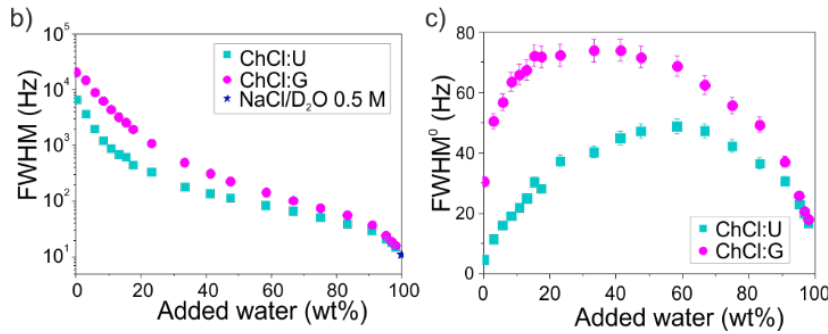
Figure 2. (a) Representative ${ }^{35} \mathrm{Cl} N M R$ spectra of $\mathrm{ChCl}: \mathrm{U}$ samples as a function of
added water content (increasing from pure DES at the top to 98.0 wt\% $\mathrm{H}_{2} \mathrm{O}$ at the added water content (increasing from pure DES at the top to $98.0 \mathrm{wt} \% \mathrm{H}_{2} \mathrm{O}$ at the in $\mathrm{D}_{2} \mathrm{O}$ in the coaxial insert. (b) Experimental log-scaled linewidth (FWHM = ful width at half maximum) and (c) viscosity-corrected linewidth $\left(\mathrm{FWHM}^{\circ}\right.$ ) for the ${ }^{35} \mathrm{C}$ signal of ChCl:U and ChCl:G samples as a function of the water content. FWHM of $\mathrm{ChCl}: U$ was corrected with viscosity data from Agieienko and Buchner. ${ }^{34}$

${ }^{35} \mathrm{Cl} \mathrm{NMR}$ spectroscopy has been used before to investigate $\mathrm{H}$-bonding and $\mathrm{Cl}^{-}$binding in a multitude of systems, with $\mathrm{Cl}^{-}$ chemical shift, linewidth and relaxation time characterising ion dynamics. ${ }^{35-43}$ Twenty samples of $\mathrm{ChCl}: \mathrm{U}$ and $\mathrm{ChCl}: \mathrm{G}$ were prepared at several dilutions, up to 98 wt $\% \mathrm{H}_{2} \mathrm{O}$ (experimental details in the ESI) $\uparrow$. Fig. 2a shows representative spectra of $\mathrm{ChCl}: U$ samples, with a large ${ }^{35} \mathrm{Cl}$ upfield shift of $\sim 50 \mathrm{ppm}$ for the most diluted sample relative to the pure DES (more details in Figs. S1-S3 and Table S5). This shift indicates substantially greater shielding of $\mathrm{Cl}^{-}$upon dilution, consistent with the stronger $\mathrm{Cl} \cdots \mathrm{H}$ interaction with water molecules. ${ }^{44}$ The ${ }^{35} \mathrm{Cl}$ linewidth is symptomatic of the $\mathrm{Cl}^{-}$bond character and local environment. ${ }^{45} \mathrm{~A}$ small quadrupolar coupling constant and thus narrow lineshapes are observed for highly symmetric scenarios, such as $\mathrm{Cl}^{-}$in isolation or with a homogeneous ligand population, due to a minimised electric field gradient. ${ }^{35}$ Decreasing the symmetry around $\mathrm{Cl}^{\text {, }}$, such as by adding a different HBD to the ligand shell, increases the quadrupolar coupling constant and broadens the NMR linewidth. ${ }^{42,46}$ Experimental linewidths at half height (FWHM) of the ${ }^{35} \mathrm{Cl}$ peaks and corresponding relaxation times $\left(\mathrm{T}_{2}\right)$ and rates $\left(\mathrm{R}_{2}\right)$ were calculated and are shown in the ESI. $\dagger$ A marked drop in linewidth and relaxation rate are observed with increasing water content (Figs. 2b, S4 and S6). The log-scaled FWHM trend shows a steep initial decrease, a second region with lesser gradient, and a third regime with steeper gradient at high dilution; these findings are consistent with stronger aqueous $\mathrm{H}$ bonding at high dilutions, where the asymmetrical network in the DES is replaced by spherically-symmetric hydrated $\mathrm{Cl}^{-39,47}$ Pioneering studies of long-chain alkylammonium chlorides showed a marked effect of the cations on the relaxation rate of
$\mathrm{Cl}^{-}$, due to asymmetric hydration of the anion in the aqueous cage around the hydrophobic cation tail. ${ }^{46}$

Because ion relaxation is closely related to the system viscosity, ${ }^{48}$ we applied a viscosity-correction to the linewidth for these viscous DESs, shown in Fig. 2c as a function of water content for both $\mathrm{ChCl}: \mathrm{U}$ and $\mathrm{ChCl}: \mathrm{G}$, using experimental viscosity data: 45

$$
\mathrm{FWHM}^{0}=\mathrm{FWHM} /\left(\eta / \eta^{0}\right)
$$

where $\eta$ is the viscosity and $\eta^{0}=1 \mathrm{cP}(1 \mathrm{mPa}$ s). For $\mathrm{ChCl}: \mathrm{U}$, linewidth corrections were derived from interpolated viscosities reported at $298.15 \mathrm{~K}$ by Agieienko and Buchner. ${ }^{34} \mathrm{We}$ experimentally verified their data, as well as other datasets, ${ }^{49,50}$ at two ChCl:U-water dilutions (Fig. S7 and S10). Without literature examples, we measured the viscosity of $\mathrm{ChCl}: \mathrm{G}$ at $298.15 \mathrm{~K}$ over the full hydration range, and interpolated the resulting data to correct the corresponding linewidths.

ChCl:G partially (auto-)esterifies; ${ }^{51}$ the resulting water release and presence of esters can significantly affect the viscosity and other physicochemical properties. ${ }^{51,52}$ Dilution with water decreases this deviation, by shifting the reaction equilibrium towards the DES components. A small ester peak was distinguishable in ${ }^{1} \mathrm{H}-\mathrm{NMR}$ spectra, under the same conditions as the viscosity and ${ }^{35} \mathrm{Cl}-\mathrm{NMR}$ measurements, for $\mathrm{ChCl}$ :G at low water contents (esterification yield of 1.5-4\%). The initial latent water content $(0.983-1.029 \mathrm{wt} \%$ for $\mathrm{ChCl}: \mathrm{U}$, 1.022-1.314 wt\% for $\mathrm{ChCl:G)} \mathrm{slightly} \mathrm{shift} \mathrm{the} \mathrm{viscosity}$ corrections at low water contents. This was not considered for the ${ }^{35} \mathrm{Cl}$ NMR experiments, but we show that this effect on the $\mathrm{FWHM}^{0}$ would be limited in Figs. S11 and S12.

The viscosity-corrected linewidths in Fig. 2c show a remarkable re-entrant behaviour as water content grows. The $\mathrm{FWHM}^{0}$ first increases up to a maximum value (ca. $40 \mathrm{wt} \%$ for

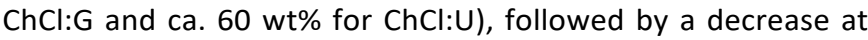
higher dilutions. In the most diluted samples, the linewidth is $\sim 15$ and $16 \mathrm{~Hz}$ for $\mathrm{ChCl}: \mathrm{U}$ and $\mathrm{ChCl}: \mathrm{G}$, respectively (respective $\mathrm{FWHM}^{0}$ of 17 and $18 \mathrm{~Hz}$ ). As $\mathrm{Cl}^{-}$approaches the Debye-Hückel limit of completely dissociated ions, i.e. predominantly hydrated $\mathrm{Cl}^{-}$at these higher dilutions, ${ }^{53}$ these FWHM match more closely the linewidths of 'free ions' (FWHM $=11 \mathrm{~Hz}$ for 0.5 $\mathrm{M} \mathrm{NaCl}$ ). Here, the ${ }^{35} \mathrm{Cl}$ coordination shell is symmetrical, leading to the narrowest possible linewidths. An artefact of our correction is a slightly narrower $\mathrm{FWHM}^{0}$ for neat $\mathrm{ChCl}: \mathrm{U}$ than for the most diluted aqueous samples ( 5 vs $17 \mathrm{~Hz}$ ). This is due to the proportionality between ionic relaxation rate and macroscopic viscosity. Future correction strategies for such viscous systems, which do not over-correct pure DES due to direct normalisation, constitute an interesting avenue.

Molecular dynamics (MD) trajectories of $10 \mathrm{~ns}$ of both DES, from 0-90.9 wt\% $\mathrm{H}_{2} \mathrm{O}$, were analysed to determine the $\mathrm{Cl}^{-}$ coordination environment. Interactions between DES components (i.e. $\mathrm{Ch}^{+}-\mathrm{Cl}^{-}, \mathrm{HBD}-\mathrm{Cl}^{-}$, and $\mathrm{HBD}-\mathrm{HBD}$ ) decrease, as expected, when water is added, 54 until the DES-DES hydrogen bonding network is disrupted, with onset around a volume fraction of $50 \% \mathrm{H}_{2} \mathrm{O} .{ }^{8}$ Further MD details, including densities, diffusion coefficients and methodology, are given in the ESI. $\dagger$ The trends in diffusivity agree with previous computations. ${ }^{54}$ 

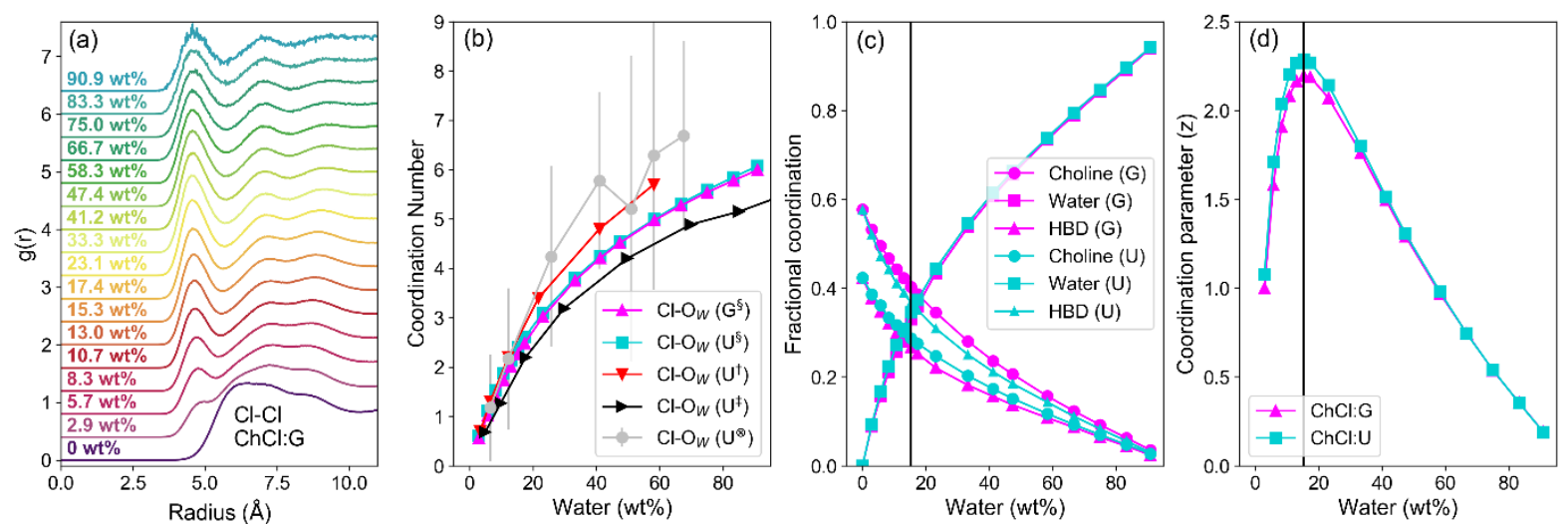

Figure 3. Data from MD simulations of $\mathrm{ChCl}: \mathrm{U}$ and $\mathrm{ChCl}: \mathrm{G}$ aqueous mixtures; (a) $\mathrm{Cl}-\mathrm{Cl}$ RDFs for the ChCl:G DES as a function of water content (increasing from bottom to top); (b) Cl-O $\mathrm{O}_{w}$ (water oxygen) coordination number as a function of water concentration for both systems, and compared with 3 literature studies of ChCl: $\mathrm{U}$ as a function of water content: ' $D$ ata from this study, ${ }^{+}$Data from Kumari et al., ${ }^{13}{ }^{\ddagger}$ Data from Harries et al., $14 \otimes$ Data from Hammond et al., 8 ; (c) Fractional coordination of each species around $\mathrm{Cl}^{-}$in both DES as a function of water content. Fractional coordination is the proportion of each species relative to the sum of all, omitting $\mathrm{Cl}^{-}-$ $\mathrm{Cl}$ - because it does not form contact pairs and thus should have minimal effect on the NMR environment; (d) calculated coordination parameter (z) as a function of water content for both DES, where the maximum shows the point at which the ligand environment is most varied. Note that the lowest water content used for the $z-$ parameter is 2.9 wt\%. Coordination numbers were calculated by integrating RDFs of atom types proximal to the molecular geometric centres; $\mathrm{N}_{4}$ for cholinium, Ow. for water, $C_{\text {To }}$ for glycolic acid. A tie line is drawn on both (c) and (d) for the concentration in both DES (15.3 wt\%) where $z$, the coordination parameter, is maximised;
lines serve otherwise as a guide to the eye.

The models show a strong contraction in the $\mathrm{Cl}^{-}-\mathrm{Cl}^{-} \mathrm{RDF}$ as water content increases, which is most prominent in $\mathrm{ChCl}: \mathrm{G}$ (Fig. 3a). The primary $\mathrm{Cl}^{-}-\mathrm{Cl}^{-}$interaction peak is diffuse in pure $\mathrm{ChCl}: \mathrm{G}$, spanning from $c a .4 .8-10 \AA$. Once water is added, the $\mathrm{Cl}^{-}$ $-\mathrm{Cl}$ peak contracts to respective onset and first minima of $c a .4$ and $6 \AA$. The closely-binned water contents studied here reveal this change even for the lowest water content of $2.9 \mathrm{wt} \% \mathrm{H}_{2} \mathrm{O}$, which is easily achieved if DES are prepared without control over water content. ${ }^{55}$ Other studies have recently noted similar phenomena in DES such as $\mathrm{ChCl}: \mathrm{U}$ and $\mathrm{ChCl}$ :Ethylene Glycol, ${ }^{13,14,54}$ though this effect appears stronger in ChCl:G.

Even at very low water contents, water is a strong ligand for chloride, binding strongly and outcompeting DES species due to its $\mathrm{H}$-bonding capability and small molecular volume. Water therefore occupies the space around $\mathrm{Cl}^{-}$anions, which helps to reduce $\mathrm{Cl}^{-}-\mathrm{Cl}^{-}$separation via bridging in solvent-separated pairs. At just 25 wt\% $\mathrm{H}_{2} \mathrm{O}$, the $\mathrm{Cl}-\mathrm{H}_{2} \mathrm{O}$ coordination number is $\approx 3$, (Fig. $3 b)$, so half-hydrated relative to $\left[\mathrm{Cl}\left(\mathrm{H}_{2} \mathrm{O}\right)_{6}\right]^{-56}$ The $\mathrm{Cl}-\mathrm{OW}$ coordination number follows the same trends for the two DESs, despite different structures and eutectic ratios. OPLS parameters with $0.8 q$ scaling of ionic species gave good agreement with previous DES $\mathrm{Cl}-\mathrm{O}$ w coordination from MD $\mathrm{MD}^{13,14}$ and neutron scattering studies. ${ }^{8}$

The strong hydration of $\mathrm{Cl}^{-}$is therefore key, but the contribution from other components is considered via the fractional coordination (Fig. 3c), i.e. the proportion of each species as a fraction of the sum of coordination numbers, excluding chloride, which is too distant to occupy the primary sphere: The linewidth of $\mathrm{Cl}^{-}$under dilute aqueous conditions was shown only to be affected by nearest neighbours, and two layers of water molecules screen this effect. ${ }^{45} \mathrm{ChCl}: \mathrm{G}$ has $x_{\mathrm{ChCl}}$ $=0.5$ as compared to $x_{\mathrm{ChCl}}=0.33$ for ChCl:U. Hence, $\mathrm{ChCl}: \mathrm{G}$ has significantly stronger $\mathrm{Ch}^{+}-\mathrm{Cl}^{-}$interaction than $\mathrm{ChCl}: \mathrm{U}$, whereas for the latter the $\mathrm{HBD}-\mathrm{Cl}^{-}$interaction is more dominant. As a result, the fractional $\mathrm{Cl}^{-}$coordination of $\mathrm{ChCl}$ and $\mathrm{HBD}$ are inverted (Fig. 3c). In both cases the $\mathrm{Cl}^{-}$-water fractional coordination follows the same trend, with the structure around $\mathrm{Cl}^{-}$rearranging to compensate for the systematic differences. In both systems, a crossover point is then reached where water begins to dominate. We therefore developed a simple coordination parameter, $z$, to describe the solvation asymmetry around $\mathrm{Cl}^{-}$, shown in Eq. 2 for our 3-component system:

$$
z=\frac{2\left(\sum n_{i}\right)}{\sum_{i \neq j} \frac{n_{i}}{n_{j}}}=\frac{2\left(n_{C h o}+n_{w}+n_{H B D}\right)}{\left(\frac{n_{w}+n_{H B D}}{n_{C h o}}\right)+\left(\frac{n_{C h o}+n_{H B D}}{n_{w}}\right)+\left(\frac{n_{C h o}+n_{w}}{n_{H B D}}\right)} \text { (2) }
$$

where $z$ is the calculated coordination parameter, and $n_{i}$ are the coordination numbers for each component in the shell, $n_{\mathrm{Cho}}, n_{\mathrm{w}}$ (water), $n_{\mathrm{HBD}}$, derived from the models. $z$ is a non-normalised numerical descriptor for the local environment of a ligated species. When one ligand dominates (such as water) $z$ is minimised, and when every ligand is a different species, $z$ is maximised. $z$ is pertinent due to the difficulties in directional structural analysis around a spherically symmetric solute. This parameter is a proxy for the asymmetry around $\mathrm{Cl}^{-}$, but the peak in $z$ is lower in water concentration than the 'true' experimental (NMR) asymmetry due to multiple possible ligand orientations, the effect of which is more profound for concentrated DES.

The calculated $z$ (Fig. 3d) follows the same re-entrant trend shown by ${ }^{35} \mathrm{Cl}$ NMR measurements. $z$ peaks at $15.3 \mathrm{wt} \% \mathrm{H}_{2} \mathrm{O}$ for both DES, or a water fractional coordination of 0.33 (Fig. 3c). The environment becomes more symmetrical as water becomes dominant. This 'intermediate' water content, with the highest asymmetry of the $\mathrm{Cl}^{-}$environment, corresponds with other observations of large water-chloride 'pearl-on-string' clusters in $\mathrm{ChCl}: \mathrm{U},{ }^{14}$ and the minimum melting temperature of $\mathrm{ChCl}$ U:water ternary systems. ${ }^{57}$ Though it is a bulk measure, the key role of $\mathrm{Cl}^{-}$is highlighted by the minimum in mixing enthalpy as a function of water content, ${ }^{58}$ which corresponds with maximum $\mathrm{Cl}^{-}$asymmetry. The mixing enthalpy then increases to a maximum at $60-70$ wt $\% \mathrm{H}_{2} \mathrm{O}$. Initial added water is therefore energetically favourable, but this ceases when it has to directly compete with the $\mathrm{HBD}, \mathrm{Ch}^{+}$, and $\mathrm{Cl}^{-}$interactions. At 25-35 wt\%, $\Delta_{\text {mix }} H=0$ coincides with a fractional water coordination around the chloride of about 0.5 (Fig. 3c). Finally, the competition between the water and DES components weakens after reaching maximum mixing enthalpy and conductivity. ${ }^{34}$ 
The unified NMR and MD analysis therefore highlights three distinct solvation regimes in DES/water mixtures:

1. In the pure/low-hydrated DES regime, the $\mathrm{Cl}^{-}$environment is mostly symmetrical, with a remarkably homogeneous solvation shell of the HBD and $\mathrm{Ch}^{+}$.

2. Increasing water content to maximum $z / \mathrm{FWHM}^{0}$ (ca. 40 wt\% for $\mathrm{ChCl}: \mathrm{G}$ and 60 wt\% for $\mathrm{ChCl}: \mathrm{U}$ ), the asymmetry around $\mathrm{Cl}^{-}$is maximised, as water competes with the HBD and $\mathrm{Ch}^{+}$.

3. Above the maximum in $z / \mathrm{FWHM}^{0}$, water dominates the ${ }^{35} \mathrm{Cl}$ local environment, maximising symmetry. This reduces the net field gradient at the $\mathrm{Cl}^{-}$nucleus, minimising linewidth. In conclusion, viscosity-corrected ${ }^{35} \mathrm{Cl}$ NMR spectroscopy and $\mathrm{MD}$ simulations elucidated three hydration regimes of $\mathrm{Cl}^{-}$in DES upon aqueous dilution. Adding water initiates asymmetric hydration around the $\mathrm{Cl}^{-}$, as it displaces DES components in the primary solvation shell, distorting the symmetry. This causes the initial rise in $\mathrm{FWHM}^{0}$, as the field gradient upon the nucleus increases. The asymmetry then decreases as water becomes the dominant ligand. Overall, these findings are in line with the debate suggesting structural heterogeneity on molecular scales in certain hydrated DESs, 59,60 and the idea of different solvation regimes in the mixtures, where chloride (and the solvent as a whole) becomes partially and then fully hydrated.

\section{Conflicts of interest}

There are no conflicts to declare.

\section{Notes and references}

1 L. J. B. M. Kollau, M. Vis, A. Van Den Bruinhorst, A. C. C. Esteves and R. Tuinier, Chem. Commun., 2018, 54, 13351-13354.

2 E. L. Smith, A. P. Abbott and K. S. Ryder, Chem. Rev., 2014, 114, 11060-11082.

3 M. A. R. Martins, S. P. Pinho and J. A. P. Coutinho, J. Solution Chem., 2019, 48, 962-982.

4 O. S. Hammond and K. J. Edler, in Deep Eutectic Solvents: Synthesis, Properties, and Applications, 2019, pp. 25-42.

5 C. Ma, A. Laaksonen, X. Ji and X. Lu, Chem. Soc. Rev., 2018, 47, 8685-8720.

6 Y. Chen, D. Yu, W. Chen, L. Fu and T. Mu, Phys. Chem. Chem. Phys., 2019, 21, 2601-2610.

7 C. R. Ashworth, R. P. Matthews, T. Welton and P. A. Hunt, Phys. Chem. Chem. Phys., 2016, 18, 18145-18160.

8 O. S. Hammond, D. T. Bowron and K. J. Edler, Angew. Chemie Int. Ed., 2017, 56, 9782-9785.

9 O. S. Hammond, D. T. Bowron and K. J. Edler, Green Chem., 2016, 18, 2736-2744.

10 E. O. Fetisov, D. B. Harwood, I.-F. W. Kuo, S. E. E. Warrag, M. C. Kroon, C. J. Peters and J. I. Siepmann, J. Phys. Chem. B, 2018, 122, 1245-1254.

11 V. Migliorati, F. Sessa and P. D'Angelo, Chem. Phys. Lett. $X$, 2019, 2, 100001-100007.

12 R. Stefanovic, M. Ludwig, G. B. Webber, R. Atkin and A. J. Page, Phys. Chem. Chem. Phys., 2017, 19, 3297-3306.

13 P. Kumari, Shobhna, S. Kaur and H. K. Kashyap, ACS Omega, 2018, 3, 15246-15255.

14 L. Sapir and D. Harries, J. Chem. Theory Comput., 2020, 16, 3335-3342.

15 E. S. C. Ferreira, I. V. Voroshylova, N. M. Figueiredo, C. M.
Pereira and M. N. D. S. Cordeiro, J. Mol. Liq., 2020, 298, 111978-111988.

16 O. S. Hammond, D. T. Bowron, A. J. Jackson, T. Arnold, A. Sanchez-Fernandez, N. Tsapatsaris, V. Garcia Sakai and K. J. Edler, J. Phys. Chem. B, 2017, 121, 7473-7483.

17 M. Gilmore, L. M. Moura, A. H. Turner, M. Swadźba-Kwaśny, S. K. Callear, J. A. McCune, O. A. Scherman and J. D. Holbrey, J. Chem. Phys., 2018, 148, 193823-193832.

18 A. Mannu, M. Ferro, G. Colombo, M. E. Di Pietro, S. Garroni and A. Mele, J. Mol. Liq., 2020, 301, 112441.

19 A. Mannu, M. E. Di Pietro and A. Mele, Molecules, 2020, 25, 111.

20 D. Smink, A. Juan, B. Schuur and S. R. A. Kersten, Ind. Eng. Chem. Res., 2019, 58, 16348-16357.

21 A. Triolo, F. Lo Celso and O. Russina, J. Phys. Chem. B, 2020, 124, 2652-2660.

22 D. Shah and F. S. Mjalli, Phys. Chem. Chem. Phys., 2014, 16, 23900-23907.

23 C. F. Araujo, J. A. P. Coutinho, M. M. Nolasco, S. F. Parker, P. J. A. Ribeiro-Claro, S. Rudic, B. I. G. Soares and P. D. Vaz, Phys. Chem. Chem. Phys., 2017, 19, 17998-18009.

24 N. López-Salas, J. M. Vicent-Luna, S. Imberti, E. Posada, M. J. Roldán, J. A. Anta, S. R. G. Balestra, R. M. Madero Castro, S. Calero, R. J. Jiménez-Riobóo, M. C. Gutiérrez, M. L. Ferrer and F. Del Monte, ACS Sustain. Chem. Eng., 2019, 7, 17565-17573.

25 R. Ahmadi, B. Hemmateenejad, A. Safavi, Z. Shojaeifard, A. Shahsavar, A. Mohajeri, M. Heydari Dokoohaki and A. R. Zolghadr, Phys. Chem. Chem. Phys., 2018, 20, 18463-18473.

26 A. Pandey and S. Pandey, J. Phys. Chem. B, 2014, 118, 1465214661.

27 E. Posada, N. López-Salas, R. J. Jiménez Riobóo, M. L. Ferrer, M. C. Gutiérrez and F. Del Monte, Phys. Chem. Chem. Phys., 2017, 19, 17103-17110.

28 C. D'Agostino, L. F. Gladden, M. D. Mantle, A. P. Abbott, E. I. Ahmed, A. Y. M. Al-Murshedi and R. C. Harris, Phys. Chem. Chem. Phys., 2015, 17, 15297-15304.

29 E. Posada, M. J. Roldán-Ruiz, R. J. Jiménez Riobóo, M. C. Gutiérrez, M. L. Ferrer and F. del Monte, J. Mol. Liq., 2019, 276, 196-203.

30 M. J. Roldán-Ruiz, R. J. Jiménez-Riobóo, M. C. Gutiérrez, M. L. Ferrer and F. del Monte, J. Mol. Liq., 2019, 284, 175-181.

31 P. L. Pisano, M. Espino, M. de los Á. Fernández, M. F. Silva and A. C. Olivieri, Microchem. J., 2018, 143, 252-258.

32 A. H. Turner and J. D. Holbrey, Phys. Chem. Chem. Phys., 2019, 21, 21782-21789.

33 F. Gabriele, M. Chiarini, R. Germani, M. Tiecco and N. Spreti, J. Mol. Liq., 2019, 291, 111301-111307.

34 V. Agieienko and R. Buchner, J. Chem. Eng. Data, 2019, 64, 4763-4774.

35 D. L. Bryce, M. Gee and R. E. Wasylishen, J. Phys. Chem. A, 2001, 105, 10413-10421.

36 M. Silva, A. M. Figueiredo and E. J. Cabrita, Phys. Chem. Chem. Phys., 2014, 16, 23394-23403.

37 H. Gustavsson and B. Lindman, J. Am. Chem. Soc., 1978, 100, 4647-4654.

38 N. Hedin, I. Furó and P. O. Eriksson, J. Phys. Chem. B, 2000, 104, 8544-8547.

39 R. C. Remsing, G. Hernandez, R. P. Swatloski, W. W. Massefski, R. D. Rogers and G. Moyna, J. Phys. Chem. B, 2008, 112, 1107111078.

40 P. G. Gordon, D. H. Brouwer and J. A. Ripmeester, ChemPhysChem, 2010, 11, 260-268.

41 V. Klimavicius, Z. Gdaniec and V. Balevicius, Spectrochim. ActaPart A Mol. Biomol. Spectrosc., 2014, 132, 879-883.

42 R. P. Chapman, C. M. Widdifield and D. L. Bryce, Prog. Nucl. Magn. Reson. Spectrosc., 2009, 55, 215-237.

43 P. M. J. Szell and D. L. Bryce, Recent advances in chlorine, bromine, and iodine solid-state NMR spectroscopy, Elsevier Ltd., 
1st edn., 2015, vol. 84.

44 R. C. Remsing, J. L. Wildin, A. L. Rapp and G. Moyna, J. Phys. Chem. B, 2007, 111, 11619-11621.

45 M. Yudasaka, T. Sugawara, H. Iwamura and T. Fujiyama, Bull. Chem. Soc. Jpn., 1981, 54, 1933-1938.

46 J. W. Akitt, in Multinuclear NMR, ed. J. Mason, Plenum Press, New York, 1987, pp. 447-461.

47 R. C. Remsing, R. P. Swatloski, R. D. Rogers and G. Moyna, Chem. Commun., 2006, 1271-1273.

48 B. C. Hall, Q. Rev. Chem. Soc., 1971, 25, 87-109.

49 H. Shekaari, M. T. Zafarani-moattar and B. Mohammadi, J. Mol. Liq., 2017, 243, 451-461.

50 Y. Xie, H. Dong, S. Zhang, X. Lu and X. Ji, 2014, 2014, 3344-3352.

51 N. Rodriguez Rodriguez, A. Van Den Bruinhorst, L. J. B. M. Kollau, M. C. Kroon and K. Binnemans, ACS Sustain. Chem. Eng., 2019, 7, 11521-11528.

52 A. Van Den Bruinhorst, T. Spyriouni, J. R. Hill and M. C. Kroon, J. Phys. Chem. B, 2018, 122, 369-379.

53 H. Wennerström, B. Lindman and S. Forsén, J. Phys. Chem., 1971, 75, 2936-2942.

54 A. T. Celebi, T. J. H. Vlugt and O. A. Moultos, J. Phys. Chem. B, 2019, 123, 11014-11025.

55 X. Meng, K. Ballerat-Busserolles, P. Husson and J.-M. Andanson, New J. Chem., 2016, 40, 4492-4499.

56 D. H. Powell, A. C. Barnes, J. E. Enderby, G. W. Neilson and P. S. Salmon, Faraday Discuss. Chem. Soc., 1988, 85, 137-146.

57 P. J. Smith, C. B. Arroyo, F. Lopez Hernandez and J. C. Goeltz, J. Phys. Chem. B, 2019, 123, 5302-5306.

58 C. Ma, Y. Guo, D. Li, J. Zong, X. Ji, C. Liu and X. Lu, J. Chem. Eng. Data, 2016, 61, 4172-4177.

59 A. Abbott, L. Aldous, N. Borisenko, S. Coles, O. Fontaine, J. D. Gamarra Garcia, R. Gardas, O. Hammond, L. J. Hardwick, P. H. Haumesser, F. Hausen, C. Horwood, J. Jacquemin, R. Jones, E. Jónsson, A. Lahiri, D. Macfarlane, G. Marlair, B. May, H. Medhi, V. H. Paschoal, J. E. S. J. Reid, T. Schoetz, K. Tamura, M. L. Thomas, S. Tiwari, B. Uralcan, A. Van Den Bruinhorst, M. Watanabe and J. Wishart, Faraday Discuss., 2018, 206, 405426.

60 L. Percevault, A. Jani, T. Sohier, L. Noirez, L. Paquin, F. Gauffre and D. Morineau, J. Phys. Chem. B, 2020, 124, 9126-9135. 